\title{
BMJ Police officers: a high-risk group open for the development of mental health disturbances? A cohort study
}

\author{
Peter G van der Velden, ${ }^{1,2,3}$ Arthur R Rademaker, ${ }^{4}$ Eric Vermetten, ${ }^{4}$ \\ Marie-Anne Portengen, ${ }^{5}$ Joris C Yzermans, ${ }^{6}$ Linda Grievink ${ }^{7}$
}

To cite: van der Velden $P G$, Rademaker AR, Vermetten $E$ et al. Police officers: a highrisk group

for the development of mental health disturbances? A cohort study. BMJ Open 2013;3:e001720

doi:10.1136/bmjopen-2012001720

- Prepublication history for this paper are available online. To view these files please visit the journal online (http://dx.doi.org/10.1136/ bmjopen-2012-001720).

Received 5 July 2012

Revised 19 November 2012 Accepted 3 December 2012

This final article is available for use under the terms of the Creative Commons Attribution Non-Commercial 2.0 Licence; see http://bmjopen.bmj.com

For numbered affiliations see end of article

Correspondence to Professor Peter G van der Velden; pg.vandervelden@ tilburguniversity.nl

\section{ABSTRACT}

Objectives: Policing is generally considered a highrisk profession for the development of mental health problems, but this assumption lacks empirical evidence. Research question of the present study is to what extent mental health disturbances, such as (very) severe symptoms of anxiety, depression and hostility are more prevalent among police officers than among other occupational groups.

Design: Multicomparative cross-sectional study using the data of several cross-sectional and longitudinal studies in the Netherlands.

Participants: Two samples of police officers ( $\mathrm{N}=144$ and 503), employees of banks ( $N=1113)$ and employees of banks who were robbed ( $N=144)$; employees of supermarkets ( $\mathrm{N}=335)$, and a psychiatric hospital ( $N=219)$, employees of a governmental social welfare organisation ( $\mathrm{N}=76)$, employees who followed a training based on rational-motive therapy to strengthen their assertiveness $(\mathrm{N}=710)$, soldiers before deployment $(\mathrm{N}=278)$ and before redeployment $(\mathrm{N}=236)$ and firefighters $(\mathrm{N}=123)$. The numbers refer to respondents with complete data.

Primary outcomes: Prevalence of severe (subclinical level) and very severe symptoms (clinical level) were computed using the Dutch norm tables (80th percentile and 95th percentile, respectively) of the Symptom Check List Revised (SCL-90-R). All comparisons were controlled for age, gender and education.

Results: Multivariate logistic regression and analyses showed that the prevalence of clinical and subclinical levels of symptoms of anxiety, depression and hostility among police officers were not significantly higher than among comparison groups. The same pattern was found for the other SCL-90-R subscales.

Conclusions: We found no indications that selfreported mental health disturbances were more prevalent among police officers than among groups of employees that are not considered high-risk groups, such as employees of banks, supermarkets, psychiatric hospital and soldiers before deployment.

Police officers are commonly considered to be a high-risk group for the development of mental health disturbances because of the various critical incidents and potential

\section{ARTICLE SUMMARY}

Article focus

- It is generally assumed that police officers, due to the specific nature of their work, are at (high) risk for the development of mental health problems.

- The results of the very limited number of studies that compared the mental health of officers with one or two comparison groups suggest that this assumption needs further proof.

- To assess this assumption, clinical as well as subclinical levels of mental health problems of officers were compared with nine other occupational groups while controlling for demographics.

Key messages

- In contrast to this generally held belief, officers did not report more (serious) mental health problems than any of the other examined groups in our multicomparative study.

- The protective effects of self-selection, the resilience of police officers and a rigorous selection process of recruits might be an explanation of the relatively low prevalence rates of mental health disturbances.

Strengths and limitations of this study

- To the best of our knowledge, this is the first multicomparative study examining to what extent clinical as well as subclinical levels of symptoms of anxiety, depression and hostility are more prevalent among police officers than among people in other occupations, while controlling for demographics.

- We did not conduct clinical interviews.

traumatic events they encounter during their career. These so-called operational stressors, such as witnessing the death of children, confrontations with victims of sexual harassment, serious traffic accidents, suicide and experiencing violence, might increase the risk of symptoms of anxiety, hostility and fatigue. A (small) minority may develop mental disorders, such as depression and post-traumatic stress disorder (PTSD). ${ }^{1-4}$ 
However, research in the past 20 years among police officers has shown that organisational stressors such as conflicts, work load and lack of support are more likely to be adverse sources of stress than operational stressors. In other words, although police officers are more frequently confronted with critical incidents than for example employees of banks or supermarkets, organisational stressors-which are not specific for the policeappear to have more impact on health and well-being than (daily) operational stressors. ${ }^{25-7}$

This may explain the outcomes of a study ${ }^{8}$ in the UK which ranked 26 professions according to their scores on general psychological well-being and physical health. The rank orders for police officers was 9th and 11th, with the first place denoting the professional occupation with the highest absolute mean score of health problems. Teachers, a professional group that is not typically associated with frequent exposure to potential traumatic stressors, ranked second on both well-being and physical health. Similarly, an earlier smaller Australian comparative study reported that police officers showed significantly more favourable levels of well-being and psychological distress than school teachers and the general population (ie, Australian norm scores). ${ }^{9}$

However, to the best of our knowledge there is no, peer reviewed-published multicomparative study that (1) statistically examined differences in symptom levels between the police and several other occupational groups while also controlling for confounding factors such as age, gender and education and (2) focused on specific mental health disturbances including subclinical and clinically relevant levels of symptoms of anxiety, depression and hostility. The aim of this comparative study was to explore self-reported mental health of police officers compared to members of other professions, to investigate whether there are empirically based indications that policing may be considered a high-risk profession for the development of mental health disturbances.

\section{METHODS}

\section{Samples and procedures}

In the present study we compared police officers with nine other occupational groups. The presented numbers of each group refer to the number of respondents of each study group with complete data.

We compared the health of two samples of officers $\left(\mathrm{N}^{\text {group1 }}=144\right.$ and $\left.\mathrm{N}^{\text {group2 }}=503\right)$ with other occupational groups. Group 1 consisted of police officers working in the eastern part of the Netherlands (region department North and East Gelderland, response $=60 \%) .{ }^{10}$ This group was originally selected in 2002 to provide reference data for group 2 to examine the consequences of the disaster and other critical incidents on health. Group 2 consisted of police officers who were involved in the Enschede fireworks disaster and its aftermath (The Netherlands, 2000), and participated in a survey 4 years postevent $(2004$, response $=80.5 \%){ }^{5}$ At that time, only one officer $(0.2 \%)$ suffered from probable disasterrelated PTSD. These studies were conducted on behalf of the Dutch Ministry of Health, Welfare and Sports.

We compared the two groups of officers with the following non-clinical groups of employees participating in various Dutch studies on health and critical incidents at work. Furthermore, data from group 6 were obtained to evaluate a training programme (see below). The year of data gathering is presented between brackets and funding for each study will be described. This study is a clear example of a data-sharing research project of the researchers involved.

- Groups 3 and 4 (1991): A nationwide sample of 1257 front office employees of savings banks, of whom $11.5 \%$ experienced one or more bank robberies $\left(\mathrm{N}^{\text {group } 3}=1113\right.$ and $\mathrm{N}^{\text {group } 4}=144$, respectively, response $\left.=71 \%\right) .{ }^{11}$ This cross-sectional study was conducted on behalf of a Savings Banks Association, the Netherlands.

- Group 5 (1996): A random sample of mental health care professionals, that is, nurses and therapists of a psychiatric hospital $\left(\mathrm{N}=219\right.$ and response=70\%). ${ }^{12}$ This cross-sectional study was conducted on behalf of a Psychiatric Hospital.

- Group 6 (1997-1998): Random sample of employees of various organisations, before participating in a Rational-motive therapy (RET) training ( $\mathrm{N}=710$, response $=74 \%)^{13}$ aimed at improving their assertiveness and well-being. The cross-sectional study was conducted on behalf of a training institute in the Netherlands.

- Groups 7 and 8 (2005-2007): Sample of 524 soldiers from a larger prospective cohort study on stressrelated disorders who were assessed prior to a 4-month deployment to Afghanistan of whom 241 were deployed before $\left(\mathrm{N}^{\text {group }}=278\right.$ and $\mathrm{N}^{\text {group8 }}=236$, respectively, response $=82.5 \%),{ }^{14}$ conducted on behalf of the Dutch Ministry of Defense.

- Group 9 (2002): Firefighters from the Utrecht firefighters department $(\mathrm{N}=123$, response $=48 \%) .{ }^{15}$ This cross sectional study was conducted on behalf of the Dutch Ministry of Health, Welfare and Sport.

- Group 10 (1995): Employees of a governmental social welfare organisation in the Western part of the Netherlands, who had direct contact with clients of the organisation $(\mathrm{N}=76$, response $=65 \%) .{ }^{16}$ This crosssectional study was conducted to finish the Occupational Physician education programme of the researcher.

- Group 11 (1996): A nationwide random sample of employees of local supermarkets $(\mathrm{N}=335$, response $=$ $88 \%) .{ }^{17}$ This cross-sectional study was conducted on behalf of a large supermarket organisation in the Netherlands.

All participants in the studies mentioned above, received written information about the scientific study aims. None of the funding organisations mentioned above were involved in the present study design, analyses and manuscript. 


\section{Measures}

Besides questions regarding age, gender and education, respondents of all groups, except for group 11, completed the total Symptom Check List Revised (SCL-90-R). ${ }^{18}{ }^{19}$ This instrument uses a five-point Likert scale (from 1, 'not at all' to 5, 'extremely') and assesses symptoms over the previous 7 days. The validity and reliability of the Dutch SCL-90-R have proven to be satisfactory. ${ }^{19}$ The Dutch cut-off scores ${ }^{19}$ from 1986 for males and females of a normal population were used to identify participants with (1) at least severe symptoms of anxiety, depression, sleeping problems and hostility (80th percentile) and (2) with very severe symptoms (95th percentile) that are clinically relevant and may be indicative for a mental disorder. Group 11 was administered a brief scale consisting of 17 random items of the SCL-90-R. Our control analyses showed that the sum score of the 17 items correlated highly with the total score of the SCL-90-R across several samples ( $r>0.95)$. Education levels differed slightly across studies. We therefore made a distinction between those with high education levels (university and higher professional education) versus low-to-medium level (all other levels).

\section{Data analyses}

Differences in demographics were assessed using $\chi^{2}$-statistics. Multivariate logistic regression analyses were used to examine to what extent very severe symptoms and severe symptoms were more prevalent among police officers, while controlling for age, gender and education level. Two composite variables on mental health were computed. The first composite variable was based on whether respondents reported very severe anxiety, very severe depression and/or very severe hostility symptoms or did not report very severe symptoms on any of these three scales. A similar composite variable was based on severe symptoms. The multivariate logistic regression analyses were repeated with these composite variables as dependent variables, and group membership, age, gender and education as independent variables (predictors). Analysis of variance (ANOVA) was used to examine differences in mean scores on the sum score of 17 items between groups 1, 2 and 11 while controlling for the same possible confounding factors. SPSS V.18.0 was used to perform the analyses.

\section{RESULTS}

The demographics are shown in table $1 \cdot \chi^{2}$-Statistics indicated that study groups differed in gender $\left(\chi^{2}=897.6\right.$, $\mathrm{df}=9, \mathrm{p}<0.001)$, age $\left(\chi^{2}=798, \mathrm{df}=18, \mathrm{p}<0.001\right)$ and educational level $\left(\chi^{2}=852.4, \mathrm{df}=9, \mathrm{p}<0.001\right)$.

The prevalence's of very severe symptoms (95th percentile) are presented (except for group 11) in table 2, as well as the adjusted ORs(Adj. ORs) and the 95\% CI. In table 3 , similar statistics are presented with respect to severe symptoms (80th percentile). A table of the bivariate ORs is available on request (see appendix A1).

Results clearly show that both groups of police officers are relatively healthy: the proportion of officers with very severe symptoms of anxiety, depression and hostility is extremely low $(\leq 1.4 \%)$. Compared to all other study groups, police officers had similar or lower prevalence of clinical levels of mental health problems according to the Adj. ORs. When using a less strict criterion of subclinical levels, that is, at least severe symptoms instead of very severe symptoms according to the norm tables, the groups of officers still ranked as groups with relatively low prevalence rates. Furthermore, the proportion of officers with severe or very severe symptoms of anxiety or depression or hostility (ie, composite variables) was not significantly higher than among other groups. Additional analyses showed similar patterns with respect to the other subscales of the SCL-90-R (data not shown).

The results of ANOVA $\left(\mathrm{F}^{\text {main }}=25.5, \mathrm{df}=2, \mathrm{p}<0.001\right)$ and post hoc analyses reveal the 2004 sample of police officers

Table 1 Gender, age and education level of study groups*

\begin{tabular}{|c|c|c|c|c|c|c|c|c|}
\hline & \multirow[b]{2}{*}{$\mathbf{N}$} & \multicolumn{2}{|c|}{ Gender (\%) } & \multicolumn{3}{|c|}{ Age, years (\%) } & \multicolumn{2}{|c|}{ Education (\%) } \\
\hline & & Males & Females & $18-30$ & $31-45$ & 46-65 & $\begin{array}{l}\text { Low } \\
\text { medium }\end{array}$ & $\begin{array}{l}\text { High } \\
\text { medium }\end{array}$ \\
\hline 1 Police officers & 144 & 86.1 & 13.9 & 4.9 & 47.9 & 47.2 & 96.5 & 3.5 \\
\hline 2 Police officers & 503 & 88.7 & 11.3 & 6.0 & 56.5 & 37.6 & 91.7 & 8.3 \\
\hline 3 Bank employees, not victim robbery & 1113 & 34.1 & 65.9 & 48.7 & 38.3 & 13.0 & 81.0 & 19.0 \\
\hline 4 Bank employees, victim robbery & 144 & 47.3 & 52.7 & 37.8 & 44.6 & 17.6 & 79.1 & 20.9 \\
\hline 5 Psychiatric hospital employees & 219 & 37.9 & 62.1 & 41.6 & 47.5 & 11.0 & 61.6 & 38.4 \\
\hline 6 Trainees AT & 710 & 68.2 & 31.8 & 29.0 & 57.9 & 13.1 & 33.8 & 66.2 \\
\hline 7 Soldiers, not deployed before & 278 & 87.8 & 12.2 & 81.3 & 14.7 & 4.0 & 88.8 & 11.2 \\
\hline 8 Soldiers, deployed before & 236 & 94.5 & 5.5 & 43.6 & 43.2 & 13.1 & 85.2 & 14.8 \\
\hline 9 Firefighters & 123 & 96.7 & 3.3 & 17.1 & 39.0 & 43.9 & 94.3 & 5.7 \\
\hline 10 Social welfare & 76 & 40.8 & 59.2 & 15.8 & 50.0 & 34.2 & 42.1 & 57.9 \\
\hline 11 Supermarkets & 335 & 56.1 & 43.9 & 100 & - & - & 86.6 & 13.4 \\
\hline Total & 3885 & 61.5 & 38.5 & 41.9 & 40.9 & 17.2 & 74.1 & 25.9 \\
\hline
\end{tabular}

${ }^{*}$ Demographic characteristics of respondents with complete data. AT, Assertiveness Training. 
Table 2 Differences in prevalence of severe anxiety, depression and/or hostility symptoms (scores 80th centile) between study groups ( $\mathrm{N}=3550$ )

Severe anxiety symptoms

Severe depression symptoms

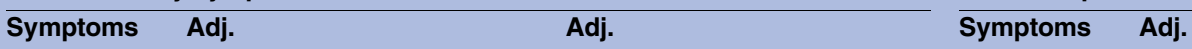

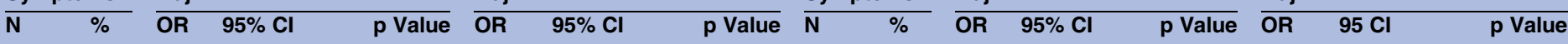

Groups

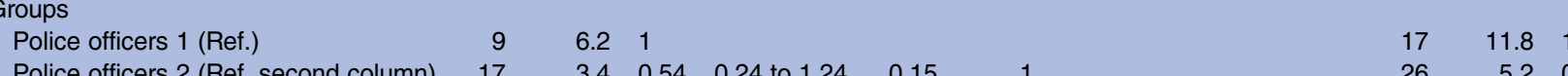

$\begin{array}{llllll}\text { Bank empl., not victim robbery } & 80 & 7.2 & 1.52 & 0.73 \text { to } 3.17 & 0.26\end{array}$

Bank empl., victim robbery

Psychiatric hospital empl.

Trainees AT

Soldiers, not deployed before

$\begin{array}{rrll}7.2 & 1.52 & 0.73 \text { to } 3.17 & 0.26 \\ 21.6 & 5.24 & 2.37 \text { to } 11.59 & 0.00\end{array}$

$\begin{array}{llll}21.6 & 5.24 & 2.37 \text { to } 11.59 & 0.00 \\ 10.0 & 2.32 & 1.01 \text { to } 5.30 & 0.05\end{array}$

$\begin{array}{llll}10.0 & 2.32 & 1.01 \text { to } 5.30 & 0.05 \\ 22.7 & 5.98 & 2.89 \text { to } 12.35 & 0.00\end{array}$

$\begin{array}{llll}6.1 & 1.02 & 0.43 \text { to } 2.42 & 0.97\end{array}$

$\begin{array}{llll}5.1 & 0.85 & 0.34 \text { to } 2.09 & 0.72\end{array}$

$\begin{array}{lllll}5.1 & 0.85 & 0.34 \text { to } 2.09 & 0.72 \\ 4.1 & 0.62 & 0.20 \text { to } 1.89 & 0.40\end{array}$

$\begin{array}{lll}17.1 & 4.32 & 1.72 \text { to } 10.88 \quad 0.00\end{array}$

$2.82 \quad 1.61$ to $4.92 \quad 0.00$

$\begin{array}{lll}9.71 & 5.14 \text { to } 18.35 & 0.00\end{array}$

$\begin{array}{lll}4.31 & 2.19 \text { to } 8.48 \quad 0.00\end{array}$

$\begin{array}{rll}11.27 & 6.53 \text { to } 19.44 \quad 0.00\end{array}$

$\begin{array}{lll}1.91 & 0.93 \text { to } 3.93 & 0.08\end{array}$

$\begin{array}{lll}1.58 & 0.74 \text { to } 3.41 & 0.24\end{array}$

$\begin{array}{lrrrr}\text { Soldiers, deployed before } & 12 & 5.1 & 0.85 & 0.34 \\ \text { Firefighters } & 5 & 4.1 & 0.62 & 0.20 \\ & 13 & 17.1 & 4.32 & 1.72\end{array}$

Social welfare

$\begin{array}{lll}1.14 & 0.41 \text { to } 3.14 & 0.81 \\ 8.04 & 3.64 \text { to } 17.77 & 0.00\end{array}$

Education

Low medium (Ref.)

High medium

$231 \quad 8.9 \quad 1$

1

Age

18-30 Ref.)

$31-35$

$46-65$

Gender

Males (Ref.)

$\begin{array}{lllll}\text { Females } & 128 & 9.5 & 0.70 & 0.53 \\ & & \text { Severe hostility symptoms }\end{array}$

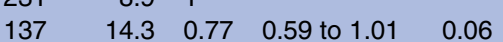

$0.75 \quad 0.57$ to $0.98 \quad 0.03$

$127 \quad 9.8 \quad 1$

$\begin{array}{rrrrr}168 & 10.6 & 0.85 & 0.60 \text { to } 1.21 & 0.36\end{array}$

$\begin{array}{llllll}1 & & & 195 & 15.1 & 1\end{array}$

$\begin{array}{llllllllll}0.36 & 0.83 & 0.58 \text { to } 1.18 & 0.29 & 266 & 16.7 & 0.86 & 0.64 \text { to } 1.15 & 0.31\end{array}$

$\begin{array}{llllllllll}0.72 & 0.52 \text { to } 0.99 & 0.04 & 111 & 16.6 & 0.76 & 0.58 \text { to } 0.99 & 0.04\end{array}$



$\begin{array}{llll}12.0 & 1.26 & 0.72 \text { to } 2.20 & 0.41\end{array}$

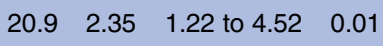

$\begin{array}{llll}16.4 & 1.82 & 0.96 \text { to } 3.46 & 0.07\end{array}$

$\begin{array}{llll}36.2 & 4.83 & 2.77 \text { to } 8.44 \quad 0.00\end{array}$

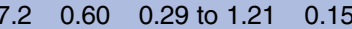

$\begin{array}{llll}7.6 & 0.63 & 0.31 \text { to } 1.29 & 0.21\end{array}$

$\begin{array}{llll}13.0 & 1.08 & 0.52 \text { to } 2.24 & 0.84\end{array}$

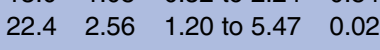



$\begin{array}{lll}4.50 & 2.59 \text { to } 7.82 \quad 0.00\end{array}$

$\begin{array}{lll}11.98 & 7.62 \text { to } 18.82 & 0.00\end{array}$

$\begin{array}{lll}1.47 & 0.78 \text { to } 2.75 & 0.23\end{array}$

$\begin{array}{lll}1.56 & 0.83 \text { to } 2.92 & 0.17\end{array}$

$\begin{array}{lll}2.60 & 1.35 \text { to } 5.03 & 0.00\end{array}$

$6.25 \quad 3.14$ to $12.45 \quad 0.00$

$240 \quad 10.9 \quad 1$

$\begin{array}{lllll} & & \text { Adj. } & \text { Symptoms Adj. } & \text { Adj. }\end{array}$

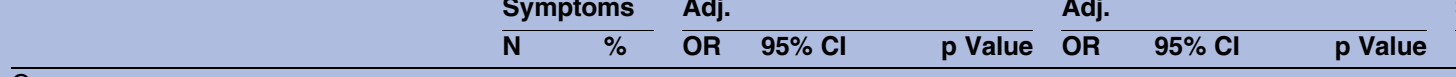

Groups

$\begin{array}{lll}16 & 11.1 & 1\end{array}$

Police officers 1 (Ref.)

Police officers 2 (Ref. second column)

Bank empl., not victim robbery

Bank empl., victim robbery

Psychiatric hospital empl.

Trainees AT

Soldiers, not deployed before

Soldier, deployed before

Firefighters

Social welfare

Education

Low medium (Ref.)

High medium

Age

18-30 (Ref.)

$31-35$

46-65

Gender

Males (Ref.)

$\begin{array}{lllll}6.6 & 0.57 & 0.30 \text { to } 1.06 & 0.08\end{array}$

1

$\begin{array}{lllll}13.5 & 1.68 & 0.96 \text { to } 2.96 & 0.07\end{array}$

$\begin{array}{llll}20.3 & 2.62 & 1.34 \text { to } 5.10 & 0.00\end{array}$

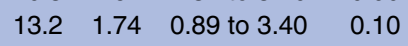

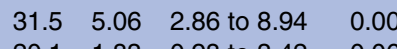

$\begin{array}{llll}20.1 & 1.83 & 0.98 \text { to } 3.42 & 0.06\end{array}$

$\begin{array}{llll}18.6 & 1.73 & 0.93 \text { to } 3.25 & 0.08\end{array}$

$\begin{array}{llll}13.8 & 1.20 & 0.58 \text { to } 2.49 & 0.63\end{array}$

$\begin{array}{llll}22.4 & 3.62 & 1.68 \text { to } 7.82 & 0.00\end{array}$

$\begin{array}{lll}2.97 & 1.96 \text { to } 4.50 & 0.00\end{array}$

$\begin{array}{lll}4.62 & 2.68 \text { to } 7.98 & 0.00 \\ 3.07 & 1.78 \text { to } 5.31 & 0.00\end{array}$

$\begin{array}{lll}3.07 & 1.78 \text { to } 5.31 & 0.00\end{array}$

$8.96 \quad 5.90$ to $13.59 \quad 0.00$

$\begin{array}{lll}3.25 & 1.99 \text { to } 5.30 \quad 0.00\end{array}$

$\begin{array}{lll}3.07 & 1.87 \text { to } 5.02 & 0.00\end{array}$

$\begin{array}{lll}3.07 & 1.87 \text { to } 5.02 & 0.00 \\ 2.13 & 1.14 \text { to } 3.97 & 0.02\end{array}$

$\begin{array}{lll}2.13 & 1.14 \text { to } 3.97 & 0.02 \\ 6.42 & 3.30 \text { to } 12.51 & 0.00\end{array}$

$\begin{array}{lll}419 & 16.2 & 1\end{array}$

$\begin{array}{lllll}197 & 20.5 & 0.70 & 0.55 \text { to } 0.88 & 0.00\end{array}$

1

$0.69 \quad 0.55$ to $0.87 \quad 0.00 \quad 313$

$234 \quad 18.1 \quad 1$

$\begin{array}{llllll}17.4 & 1.12 & 0.84 \text { to } 1.49 & 0.46\end{array}$

1

$\begin{array}{llll}1.13 & 0.84 \text { to } 1.51 & 0.43 & 346\end{array}$

$\begin{array}{llll}0.94 & 0.72 \text { to } 1.23 & 0.65 & 155\end{array}$

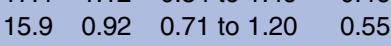

1

$\begin{array}{llll}0.55 & 0.44 \text { to } 0.69 \quad 0.00 \quad 698\end{array}$

$\begin{array}{lll}698 & 27.1 & 1 \\ 306 & 22.7 & 0.68\end{array}$

Females ${ }^{*}$ Anxiety and/or depression and/or hostility.

Adj. OR, OR adjusted for all study variables; AT, Assertiveness Training; empl., employee; Ref., reference group.

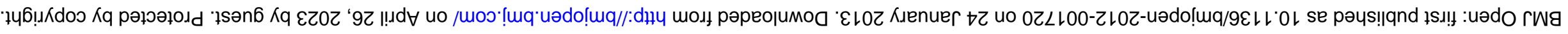

0.58 to $0.90 \quad 0.00$ evere symptoms composite variable

$\begin{array}{ll}18.1 & 1\end{array}$

$\begin{array}{llll}9.7 & 0.49 & 0.29 \text { to } 0.83 & 0.01\end{array}$

$\begin{array}{lllll}21.2 & 1.49 & 0.94 \text { to } 2.38 & 0.09\end{array}$

$\begin{array}{llll}33.1 & 2.66 & 1.52 \text { to } 4.64 & 0.00\end{array}$

$\begin{array}{llll}23.7 & 1.78 & 1.03 \text { to } 3.08 & 0.04\end{array}$

$\begin{array}{llll}46.2 & 4.66 & 2.90 \text { to } 7.49 & 0.00\end{array}$

$\begin{array}{llll}23.7 & 1.26 & 0.74 \text { to } 2.14 & 0.40\end{array}$

$\begin{array}{llll}22.0 & 1.20 & 0.70 \text { to } 2.05 & 0.50\end{array}$

$\begin{array}{lllll}20.3 & 1.09 & 0.59 & \text { to } 2.01 & 0.79\end{array}$

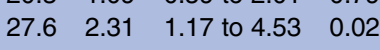

$0.99 \quad 0.79$ to $1.24 \quad 0.90$

1

$\begin{array}{lll}0.81 & 0.60 \text { to } 1.10 \quad 0.17\end{array}$

$0.72 \quad 0.55$ to $0.94 \quad 0.02$

$0.72 \quad 0.58$ to $0.91 \quad 0.01$

$\quad 95 \mathrm{Cl} \quad \mathrm{p}$ Value

\begin{tabular}{lll}
\hline .05 & 2.15 to $4.33 \quad 0.00$
\end{tabular}

$\begin{array}{lll}5.43 & 3.42 \text { to } 8.63 & 0.00\end{array}$

$\begin{array}{lll}3.66 & 2.34 \text { to } 5.72 & 0.00\end{array}$

$9.59 \quad 6.71$ to $13.71 \quad 0.00$

$\begin{array}{lll}2.59 & 1.68 \text { to } 3.99 & 0.00\end{array}$

$\begin{array}{lll}2.47 & 1.60 \text { to } 3.81 & 0.00\end{array}$

$\begin{array}{lll}2.21 & 1.30 \text { to } 3.75 & 0.00\end{array}$

$4.71 \quad 2.58$ to $8.59 \quad 0.00$

$0.84 \quad 0.69$ to $1.02 \quad 0.08$

$\begin{array}{lll}1.08 & 0.84 \text { to } 1.40 & 0.55\end{array}$

$0.87 \quad 0.69$ to $1.10 \quad 0.25$

$0.64 \quad 0.53$ to $0.78 \quad 0.00$ 
Table 3 Differences in prevalence of very severe anxiety, depression and/or hostility symptoms (scores 95th centile) between study groups ( $N=3550$ )

\begin{tabular}{|c|c|c|c|c|c|c|c|c|c|c|c|c|c|c|c|c|}
\hline & \multicolumn{8}{|c|}{ Very severe anxiety symptoms } & \multicolumn{8}{|c|}{ Very severe depression symptoms } \\
\hline & \multicolumn{2}{|c|}{ Symptoms } & \multicolumn{3}{|l|}{ Adj. } & \multicolumn{3}{|l|}{ Adj. } & \multicolumn{2}{|c|}{ Symptoms } & \multicolumn{3}{|l|}{ Adj. } & \multicolumn{3}{|l|}{ Adj. } \\
\hline & $\overline{\mathbf{N}}$ & $\%$ & $\overline{O R}$ & $95 \% \mathrm{Cl}$ & p Value & OR & $95 \% \mathrm{Cl}$ & p Value & $\mathbf{N}$ & $\%$ & OR & $95 \% \mathrm{Cl}$ & p Value & OR & $95 \% \mathrm{Cl}$ & p Value \\
\hline \multicolumn{17}{|l|}{ Groups } \\
\hline Police officers 1 (Ref.) & 2 & 1.4 & 1 & & & & & & 2 & 1.4 & 1 & & & & & \\
\hline Police officers 2 (Ref. second column) & 3 & 0.6 & 0.41 & 0.07 to 2.50 & 0.34 & 1 & & & 6 & 1.2 & 0.86 & 0.17 to 4.32 & 0.86 & 1 & & \\
\hline Bank empl., not victim robbery & 9 & 0.8 & 0.73 & 0.15 to 3.56 & 0.69 & 1.74 & 0.45 to 6.78 & 0.42 & 30 & 2.7 & 2.09 & 0.48 to 9.03 & 0.33 & 2.41 & 0.96 to 6.02 & 0.06 \\
\hline Bank empl., victim robbery & 7 & 4.7 & 4.08 & 0.81 to 20.62 & 0.09 & 9.81 & 2.44 to 39.50 & 0.00 & 13 & 8.8 & 7.22 & 1.58 to 33.11 & 0.01 & 8.35 & 3.06 to 22.80 & 0.00 \\
\hline Psychiatric hospital empl. & 1 & 0.5 & 0.38 & 0.03 to 4.41 & 0.44 & 0.91 & 0.09 to 9.12 & 0.94 & 13 & 5.9 & 4.92 & 1.07 to 22.71 & 0.04 & 5.68 & 2.06 to 15.64 & 0.00 \\
\hline Trainees AT & 32 & 4.5 & 3.20 & 0.70 to 14.53 & 0.13 & 7.67 & 2.18 to 27.04 & 0.00 & 69 & 9.7 & 8.39 & 1.97 to 35.67 & 0.00 & 9.70 & 4.02 to 23.44 & 0.00 \\
\hline Soldiers, not deployed before & 2 & 0.7 & 0.54 & 0.07 to 4.14 & 0.55 & 1.30 & 0.20 to 8.38 & 0.78 & 1 & 0.4 & 0.22 & 0.02 to 2.52 & 0.22 & 0.26 & 0.03 to 2.19 & 0.21 \\
\hline Soldiers, deployed before & 0 & 0.0 & NA & & & & & & 2 & 0.8 & 0.56 & 0.08 to 4.09 & 0.57 & 0.65 & 0.13 to 3.30 & 0.61 \\
\hline Firefighters & 0 & 0.0 & NA & & & & & & 2 & 1.6 & 1.12 & 0.15 to 8.06 & 0.91 & 1.30 & 0.26 to 6.52 & 0.75 \\
\hline Social welfare & 1 & 1.3 & 1.04 & 0.09 to 12.24 & 0.97 & 2.50 & 0.25 to 25.41 & 0.44 & 4 & 5.3 & 4.63 & 0.81 to 26.49 & 0.08 & 5.34 & 1.43 to 19.96 & 0.01 \\
\hline \multicolumn{17}{|l|}{ Education } \\
\hline Low medium (Ref.) & 29 & 1.1 & 1 & & & & & & 82 & 3.2 & 1 & & & & & \\
\hline High medium & 28 & 2.9 & 1.19 & 0.64 to 2.21 & 0.58 & 1.20 & 0.64 to 2.24 & 0.56 & 60 & 6.2 & 0.87 & 0.59 to 1.30 & 0.50 & 0.87 & 0.59 to 1.30 & 0.51 \\
\hline \multicolumn{17}{|l|}{ Age } \\
\hline 18-30 (Ref.) & 16 & 1.2 & 1 & & & & & & 52 & 4.0 & 1 & & & & & \\
\hline $31-35$ & 32 & 2.0 & 0.98 & 0.40 to 2.42 & 0.96 & 0.99 & 0.39 to 2.49 & 0.98 & 67 & 4.2 & 1.18 & 0.68 to 2.04 & 0.56 & 1.18 & 0.68 to 2.05 & 0.57 \\
\hline $46-65$ & 9 & 1.3 & 1.15 & 0.53 to 2.49 & .72 & 1.16 & 0.52 to 2.59 & 0.71 & 23 & 3.4 & 0.93 & 0.56 to 1.53 & 0.76 & 0.92 & 0.56 to 1.54 & 0.76 \\
\hline \multicolumn{17}{|l|}{ Gender } \\
\hline Males (Ref.) & 41 & 1.9 & 1 & & & & & & 86 & 3.9 & 1 & & & & & \\
\hline \multirow[t]{4}{*}{ Females } & 16 & 1.2 & 0.61 & 0.32 to 1.17 & 0.14 & 0.62 & 0.32 to 1.19 & 0.15 & 56 & 4.2 & 0.79 & 0.53 to 1.18 & 0.25 & 0.80 & 0.54 to 1.19 & 0.27 \\
\hline & \multicolumn{8}{|c|}{ Very severe hostility symptoms } & \multicolumn{8}{|c|}{ Very severe symptoms composite variable } \\
\hline & \multicolumn{2}{|c|}{ Symptoms } & \multicolumn{3}{|l|}{ Adj. } & Adj. & & & Sym & & Adj. & & & Adj. & & \\
\hline & $\overrightarrow{\mathrm{N}}$ & $\%$ & OR & $95 \% \mathrm{Cl}$ & $p$ Value & OR & $95 \% \mathrm{Cl}$ & $p$ Value & $\mathbf{N}$ & $\%$ & OR & $95 \% \mathrm{Cl}$ & p Value & $\overline{O R}$ & $95 \% \mathrm{Cl}$ & p Value \\
\hline Groups & & & & & & & & & & & & & & & & \\
\hline Police officers 1 (Ref.) & 2 & 1.4 & 1 & & & & & & 3 & 2.1 & 1 & & & & & \\
\hline Police officers 1 (Ref. second column) & 5 & 1.0 & 0.73 & 0.14 to 3.79 & 0.70 & 1 & & & 7 & 1.4 & 0.67 & 0.17 to 2.62 & 0.56 & 1 & & \\
\hline Bank empl., not victim robbery & 28 & 2.5 & 1.67 & 0.38 to 7.31 & 0.50 & 2.25 & 0.83 to 6.12 & 0.11 & 51 & 4.6 & 2.31 & 0.70 to 7.64 & 0.17 & 3.42 & 1.50 to 7.78 & 0.00 \\
\hline Bank empl., victim robbery & 9 & 6.1 & 4.41 & 0.92 to 21.20 & 0.06 & 5.97 & 1.92 to 18.54 & 0.00 & 19 & 12.8 & 7.16 & 2.04 to 25.10 & 0.00 & 10.63 & 4.31 to 26.21 & 0.00 \\
\hline Psychiatric hospital empl. & 7 & 3.2 & 2.40 & 0.48 to 12.07 & 0.29 & 3.23 & 0.98 to 10.65 & 0.05 & 16 & 7.3 & 4.02 & 1.13 to 14.36 & 0.03 & 5.95 & 2.36 to 15.05 & 0.00 \\
\hline Trainees AT & 44 & 6.2 & 5.71 & 1.32 to 24.72 & 0.02 & 7.71 & 2.90 to 20.49 & 0.00 & 96 & 13.5 & 8.38 & 2.55 to 27.51 & 0.00 & 12.43 & 5.55 to 27.83 & 0.00 \\
\hline Soldiers, not deployed before & 7 & 2.5 & 1.26 & 0.25 to 6.42 & 0.78 & 1.70 & 0.51 to 5.72 & 0.39 & 8 & 2.9 & 1.12 & 0.29 to 4.43 & 0.87 & 1.67 & 0.58 to 4.82 & 0.34 \\
\hline Soldiers, deployed before & 4 & 1.7 & 1.02 & 0.18 to 5.75 & 0.99 & 1.38 & 0.36 to 5.30 & 0.64 & 6 & 2.5 & 1.10 & 0.27 to 4.54 & 0.89 & 1.64 & 0.54 to 5.00 & 0.38 \\
\hline Firefighters & 2 & 1.6 & 1.07 & 0.15 to 7.76 & 0.94 & 1.49 & 0.28 to 7.78 & 0.64 & 3 & 2.4 & 1.11 & 0.22 to 5.59 & 0.90 & 1.66 & 0.42 to 6.51 & 0.47 \\
\hline Social welfare & 7 & 9.2 & 9.20 & 1.81 to 46.91 & 0.01 & 12.57 & 3.73 to 42.40 & 0.00 & 9 & 11.8 & 7.68 & 1.97 to 29.89 & 0.00 & 11.41 & 4.01 to 32.45 & 0.00 \\
\hline Education & & & & & & & & & & & & & & & & \\
\hline Low medium (Ref.) & 78 & 3.0 & 1 & & & 1 & & & 134 & 5.2 & 1 & & & & & \\
\hline High medium & 37 & 3.9 & 0.62 & 0.39 to 0.99 & 0.05 & 0.62 & 0.39 to 0.99 & 0.05 & 84 & 8.7 & 0.79 & 0.56 to 1.10 & 0.16 & 0.79 & 0.56 to 1.10 & 0.16 \\
\hline Age & & & & & & & & & & & & & & & & \\
\hline 18-30 (Ref.) & 53 & 4.1 & 1 & & & 1 & & & 88 & 6.8 & 1 & & & & & \\
\hline $31-35$ & 44 & 2.8 & 1.56 & 0.85 to 2.85 & 0.15 & 1.67 & 0.89 to 3.11 & 0.11 & 96 & 6.0 & 1.28 & 0.82 to 2.02 & 0.28 & 1.31 & 0.83 to 2.06 & 0.25 \\
\hline $46-65$ & 18 & 2.7 & 0.87 & 0.49 to 1.54 & 0.63 & 0.95 & 0.52 to 1.72 & 0.86 & 34 & 5.1 & 0.92 & 0.60 to 1.39 & 0.69 & 0.94 & 0.61 to 1.44 & 0.77 \\
\hline Gender & & & & & & & & & & & & & & & & \\
\hline Males (Ref.) & 66 & 3.0 & 1 & & & 1 & & & 130 & 5.9 & 1 & & & 1 & & \\
\hline Females & 49 & 3.6 & 0.87 & 0.55 to 1.35 & 0.53 & 0.88 & 0.56 to 1.37 & 0.56 & 88 & 6.5 & 0.81 & 0.58 to 1.12 & 0.20 & 0.81 & 0.59 to 1.13 & 0.22 \\
\hline
\end{tabular}

${ }^{*}$ Anxiety and/or depression and/or hostility.

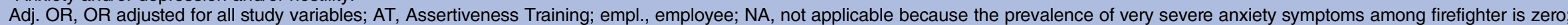
Ref., reference group. 
to exhibit significantly lower mean scores on the 17 -item sum score than employees of supermarkets, while the 2002 sample did not differ significantly from supermarket employees (Police ${ }^{2002}$ : $\mathrm{M}=20.7, \quad \mathrm{SD}=5.9 ; \quad$ Police $^{2004}$ : $\mathrm{M}=18.9, \mathrm{SD}=4.37$; Super market: $\mathrm{M}=22.6, \mathrm{SD}=7.28$ ).

\section{DISCUSSION}

We found no indications that subclinical mental health problems, that is, severe symptoms were more prevalent among police officers than among other occupational groups in our comparative study. The same pattern was observed with respect to very severe symptoms, that is, a level of self-reported symptoms that may be indicative of the presence of mental disorders such as generalised anxiety disorder or major depressive disorder. Surprisingly, findings showed that officers in our comparative study were as healthy as study groups that are not considered high-risk professions, such as employees of banks (not victimised by robberies), supermarket employees, mental health-care professionals and soldiers before deployment. Moreover, they strongly differed from employees participating in an RET training because of mental health problems that were associated with a lack of assertiveness. Although we are not aware of a similar multicomparative study, these findings appear to be in line with the outcomes of a Dutch study on burnout among officers showing that officers had lower levels of emotional exhaustion than one large reference group consisting of various occupations, ${ }^{20}$ a Norwegian study ${ }^{1}$ showing that officers exhibited lower levels of emotional exhaustion (but higher levels of depersonalisation) than physicians, and the outcomes of the aforementioned studies. ${ }^{8}{ }^{9}$ However, these studies did not control of adjust for the possible confounding effects of demographics in contrast to our study.

How can these findings be explained? In the Dutch situation police officers follow a rigorous selection process: about $90 \%$ of those applying to the officer training programme is rejected (personal communication Dr Annika Smit, Dutch Police Academy). Moreover, officers are trained to deal and cope with critical incidents and as a consequence may be highly resilient to mental health problems. $^{21}$ This may explain why bank employees (not selected to cope with severe incidents nor trained as rigorously as police officers), who were confronted with bank robberies reported significantly more (severe and very severe) mental health disturbances.

Interestingly, in an older prospective study among police officers involved as body handlers in a disaster, no increases in health problems compared with predisaster levels were observed. ${ }^{22}$ These findings seriously question the generally held belief that policing is a high-risk profession with respect to mental health: is it perhaps a (partial) myth? Either way, it reminds us of the debate on suicide among officers that once (in fact) has been described as an epidemic. ${ }^{23}$ However, the critical review on suicide among officers of Hem et $a t^{23}$ clearly demonstrated that no evidence of an elevated suicide rate among officers actually exists and that previous research had serious methodological shortcomings.

Despite the strength of our study, that is, multiple comparison groups and controlling for age, gender and education, some possible limitations and characteristics should be discussed. First, although very high scores on the SCL-90-R (very severe symptoms) may be indicative of a mental disorder, we did not conduct clinical interviews to examine the prevalence of mental disorders such as generalised anxiety, major depression and PTSD across samples. Very severe symptoms are considered to be clinically relevant. According to the Dutch norm tables $^{19}$ the mean scores of a norm group of psychiatric patients on the subscales anxiety and depression were $26.0(\mathrm{SD}=9.9)$ and $41.9(\mathrm{SD}=14.8)$, respectively. In our total sample the mean scores of those with very severe anxiety and depression symptoms were 27.7 ( $\mathrm{SD}=5.2)$ and $43.3(\mathrm{SD}=8.1)$, respectively. Therefore, it is not very likely that the prevalence rates obtained from clinicianrated instruments would be (much) higher than the prevalence rates obtained by self-report measures such as the SCL-90-R. ${ }^{24}$

Second, we were not able to compare the prevalence of PTSD across our study samples. Therefore, it is possible that the prevalence of PTSD among police officers is higher than among the other study groups. However, given the marked overlap of PTSD symptoms with other disorders and the typical comorbidity rates of PTSD with for instance depression, ${ }^{25} 26$ it is unlikely that police officers with PTSD, did not suffer from other severe mental health disturbances. Indeed, a large study among UK military personnel $(\mathrm{N}=10069)^{27}$ showed that 344 of the 394 PTSD cases $(87.3 \%)$ reported severe mental health problems, that is, were GHQ cases (high scores on the General Health Questionnaire). Only a small group of PTSD cases $(\mathrm{N}=50,12.7 \%)$ were not identified as being a GHQ case (prof. Roberto Rona, personal communication). Control analyses among another sample $(\mathrm{N}=67)$ of Dutch employees seeking treatment at the Institute for Psychotrauma for (probable) PTSD following various traumatic events, showed similar results. In total, $86.6 \%$ $(\mathrm{N}=58)$ of the (probable) PTSD cases $(\mathrm{N}=67$, Scores on the Impact of Event Scale of 35 or more ${ }^{28}$ ) also reported very severe mental health problems according to our composite variable of very severe symptoms. These findings are in line with previous research, ${ }^{29} 30$ demonstrating that PTSD and SCL-90-R scores are strongly associated. Thus, an increased prevalence rate for PTSD in the absence of marked mental health problems would be highly unlikely.

Third, the two groups of officers were not drawn from national samples of officers. Group 1 was obtained in the eastern part of the Netherlands, but group 2 consisted of officers from several regions in the Netherlands (mainly east, mid and west). We have no data on the non-response of group 1. Although both groups did not differ in prevalence rates of very severe anxiety, depression and hostility 
symptoms (ie, clinical level of symptoms), significant differences were found in the prevalence of severe depression symptoms (80th percentile). This may reflect the normal variety of the prevalence of symptoms among subsamples within one occupational group. In addition, table 2 showed that females in our study less often had severe symptoms than males (although the prevalence of very severe symptoms did not differ between both subgroups) while in the general population the opposite is found. ${ }^{19}$ However, our study samples do not reflect the general population (see table 1). We used the Dutch norm tables for males and females: the cuf-offs scores for females are slightly higher than for males to enable such comparisons. ${ }^{19}$

Finally, one could hypothesise that the data of our study groups were not obtained very recently and that for instance the current prevalence of mental health problems among police officers is (much) higher. The data were in fact obtained in the period 1991-2007. It is possible in principle that the stability of the prevalence of assessed clinical and subclinical symptoms varied across the study groups during this period. Therefore we cannot rule out the possibility that for instance mental health problems among police officers increased over these years, while those of bank employees decreased and those of soldiers remained stable. Unfortunately, we are not aware of any study assessing and demonstrating differences in trajectories of prevalence between the study groups over a period of 16 years. However, epidemiological studies among the general population examining 12-month prevalence of mental disorders may shed more light on this issue. Kessler $e t a l^{31}$ showed that the 12-month prevalence of any mental disorder was more or less stable over a 10 -year period, that is, $29.5 \%$ and $26.2 \%$, respectively. With respect to the Netherlands, the NEMESIS study ${ }^{32}$ showed similar outcomes: in contrast to the expectations of mental health professional the 12-months prevalence remained stable at about $17 \%^{33}$ in a similar period. These important results suggest that, although the studies were conducted among the general population, it is more likely that the prevalence of assessed mental health problems was relatively stable and did not differ significantly across occupational groups over time.

Participants of all 11 study groups were inhabitants of the Netherlands. Therefore, future research is warranted to examine to what extent our findings can be generalised to countries with different political, social, medical and legal systems, and selection and training procedures of officers. We were not able to control for other influential factors such as organisational characteristics. Finally, we did not examine the extent of substance use such as the consumption of alcohol and smoking. Although the outcomes of Sterud $e t a l^{34}$ did not support the notion of a strong relationship between occupational stress and alcohol use in police officers, it is unclear as to whether alcohol use differs from the other groups in our study.

\section{CONCLUSIONS}

Despite these limitations, the present study demonstrates that, although policing is generally viewed as a high-risk profession, mental health disturbances are not more prevalent in police officers as compared with various other occupational cohorts in our study. Several of these groups such as bank employees (not being robbed) and supermarket employees, as well as soldiers before deployment are typically not considered to be 'high-risk professions'. These findings suggest that the positive effects on the mental health of police offices of the selection process, self-selection and resilience, given the amount of potential stressful and traumatic events they encounter during their career, should not be underestimated.

\section{Author affiliations}

${ }^{1}$ Institute for Psychotrauma, Diemen, The Netherlands

${ }^{2}$ INTERVICT, Tilburg University, Tilburg, The Netherlands

${ }^{3}$ Arq Psychotrauma Expert Group, Diemen, The Netherlands

${ }^{4}$ Military Mental Health Research Center and University Medical Center Utrecht, Utrecht, The Netherlands

${ }^{5}$ Occupational health services ARBOUNIE, Dordrecht, The Netherlands

${ }^{6}$ The Netherlands Institute for Health Services Research, Utrecht, The Netherlands

${ }^{7}$ National Institute for Public Health and the Environment, Bilthoven, The Netherlands

Acknowledgements We would like to express our gratitude to Professor RJ Rona (Institute of Psychiatry, King's College London) for his courteous help that is, providing us the cross tabulation data on PTSD and GHQ cases among UK military. In addition, we like to thank M Bosmans (MSc) and A Pemberton (PhD, INTERVICT, Tilburg University) for their help and support and $\mathrm{A}$ Smit (PhD, Dutch Police Academy) for providing information on the selection process of officers.

Contributors PGV, designed the present multicomparative study in collaboration with all other authors, and wrote the first draft. He conducted the statistical analyses in collaboration with ARR. All authors were involved in interpreting the results of the analyses and writing the final version of the manuscript. All authors approved the final version. The data of this multicomparative study were obtained from previous studies from PGV, ARR, EV, M-AP and LG.

Funding This research received no specific grant from any funding agency in the public, commercial or not-for-profit sectors.

Competing interests None.

Ethics approval This multicomparative cohort study contains eight different occupational groups, obtained from previous research. For three study groups (police and firefighters) approval from an ethics committee was obtained that is, of TNO Bilthoven, The Netherlands. For the soldier study groups, approval was obtained from the institutional review board of the University Medical Center Utrecht, The Netherlands. For the other studies (or groups), due to the nature of the study, no approval was needed.

Provenance and peer review Not commissioned; externally peer reviewed.

Data sharing statement There are no additional data available.

\section{REFERENCES}

1. Berg AM, Hem E, Lau B, et al. An exploration of job stress and health in the Norwegian police service: cross sectional study. J Occup Med Toxicol 2006;1:26.

2. Maguen S, Metzler TJ, McCaslin SE, et al. Routine work environment stress and PTSD symptoms in police officers. J Nerv Ment Dis 2009;197:754-60. 
3. Stephens C, Miller I. Traumatic experiences and posttraumatic stress disorder in the New Zealand police. Policing 1998;21:178-91.

4. Hartley TA, Violanti JM, Fekedulegn D, et al. Associations between major life events, traumatic incidents, and depression among Buffalo police officers. Int J Emerg Ment Health 2007;9:25-35.

5. van der Velden PG, Kleber RJ, Grievink L, et al. Confrontations with aggression and mental health problems in police officers: the role of organizational stressors, life-events and previous mental health problems. Psychol Trauma Theory Res Pract Policy 2010;2:135-44.

6. Liberman AM, Best SR, Metzler TJ, et al. Routine occupational stress and psychological distress in police. Policing 2002;25:421-39.

7. Huddleston L, Stephens C, Paton D. An evaluation of traumatic and organizational experiences on the psychological health of $\mathrm{New}$ Zealand police recruits. Work 2007;28:199-207.

8. Johnson S, Cooper C, Cartwright S, et al. The experience of work-related stress across occupations. J Manag Psychol 2005;20:178-87.

9. Hart PM, Wearing AJ, Headey B. Police stress and well-being: integrating personality, coping and daily work experiences. J Occup Organ Psychol 1995;68:133-65.

10. van der Velden PG, Grievink L, Dusseldorp A, et al. Health victims Enschede fireworks disaster (In Dutch). Zaltbommel/Bilthoven, The Netherlands: Instituut voor Psychotrauma (IvP)/Rijksinstituut voor Volksgezondheid en Milieu (RIVM), 2002.

11. van der Velden PG, van der Burg S, Steinmetz CHD, et al. Victim of bank robberies (In Dutch). Houten, the Netherlands: Bohn Stafleu Van Loghem, 1992.

12. van der Velden PG, Herpers TMM. Aggression in a psychiatric hospital (in Dutch). Gedrag Gezondheid 1994;5:209-18.

13. van der Velden PG, Kleber RJ, van Oostrom I. StressMonitor manual (In Dutch) Zaltbommel, The Netherlands: Instituut voor Psychotrauma/S\&N, 2000

14. Rademaker AR, van Zuiden M, Vermetten E, et al. Type D personality and the development of PTSD symptoms: a prospective study. J Abnorm Psychol 2011;120:299-307.

15. van der Velden PG, Christiaanse B, Kleber RJ, et al. The effects of disaster exposure and post-disaster critical incidents on intrusions, avoidance and health problems among firefighters: a comparative study. Stress Trauma Crisis Int J 2006;9:73-93.

16. Portengen MAF. Aggression and violence in social welfare (In Dutch). Amsterdam, The Netherlands: Corvu/AMC Amsterdam, 1995.

17. van der Velden PG. Investigation of unsafe situations in supermarkets (In Dutch). Zaltbommel, The Netherlands: Instituut voor Psychotrauma, 1996.

18. Derogatis LR. SCL-90-R: administration, scoring and procedures manual-I for the R(evised) version. Baltimore, USA: Johns Hopkins University School of Medicine, Clinical Psychometrics Research Unit, 1977.

19. Arrindell WA, Ettema JHM. SCL-90-R manual (In Dutch). Amsterdam/Lisse, The Netherlands: Swets \& Zeitlinger/Swets Test publishers, 1986 and 2003
20. Kop N, Euwema M, Schaufeli W. Burnout, job stress and violent behavior among Dutch police officers. Work Stress 1999;13:326-40.

21. Galatzer-Levy IR, Madan A, Neylan TC, et al. Peritraumatic and trait dissociation differentiate police officers with resilient versus symptomatic trajectories of posttraumatic stress symptoms. J Trauma Stress 2011;24:557-65

22. Alexander DA, Wells A. Reactions of police officers to body handling after a major disaster: a before and after comparison. $\mathrm{Br} J$ Psychiatry 1991:159:547-55.

23. Hem E, Berg AM, Ekeberg AO. Suicide in police-a critical review. Suicide Life Threat Behav 2001;31:224-33.

24. Engelhard IM, van den Hout MA, Weerts J, et al. Deployment-related stress and trauma in Dutch soldiers returning from Iraq. Prospective study. Br J Psychiatry 2007;191:140-5.

25. Deering CG, Glover SG, Ready D, et al. Unique patterns of comorbidity in posttraumatic stress disorder from different sources of trauma. Compr Psychiatry 1996;37:336-46.

26. Blanchard EB, Buckley TC, Hickling EJ, et al. Posttraumatic stress disorder and comorbid major depression: is the correlation an illusion? J Anxiety Disord 1998;12:21-37.

27. Rona RJ, Jones M, Iversen A, et al. The impact of posttraumatic stress disorder on impairment in the UK military at the time of the Iraq war. J Psychiatry Res 2009;43:649-55.

28. Neal LA, Busutti W, Rollins JI, et al. Convergent validity of measures of post-traumatic stress disorder in a mixed military and civilian population. J Trauma Stress 1994;7:447-55.

29. Saunders BE, Arata Mandoki C, Kilpatrick D. Development of a crime-related post-traumatic stress disorder scale for women within the symptom checklist-90-revised. J Trauma Stress 1990;3:439-48.

30. Weathers FW, Litz BT, Keane TM, et al. The utility of the SCL-90-R for the diagnosis of war-zone related posttraumatic stress disorder. J Trauma Stress 1996;9:111-28.

31. Kessler RC, Chiu WT, Demler O, et al. Prevalence, severity, and comorbidity of 12-month DSM-IV disorders in the National Comorbidity Survey Replication. Arch Gen Psychiatry 2005:62:617-27.

32. Vollebergh WAM, ledema J, Bijl RV, et al. The structure and stability of common mental disorders: the Nemesis-study. Arch Gen Psychiatry 2001;58:597-603.

33. de Graaf R, ten Have M, van Dorsselaer S. De psychische gezondheid van de Nederlandse bevolking NEMESIS-2: Opzet en eerste resultaten [The mental health of the Dutch population NEMISIS-2: Design and first results. In Dutch]. Utrecht, The Netherlands: Trimbos.

34. Sterud T, Hem E, Ekeberg O, et al. Occupational stress and alcohol use: a study of two nationwide samples of operational police and ambulance, personnel in Norway. Stud Alcohol Drugs 2007;68:896-904.

\section{APPENDIX A1}

Table A1 
Table A1 Bivariate associations between predictors and dependent variables

\begin{tabular}{|c|c|c|c|c|c|c|c|c|c|c|c|c|c|c|c|c|}
\hline & \multicolumn{4}{|c|}{ Severe anxiety symptoms } & \multicolumn{4}{|c|}{$\begin{array}{l}\text { Severe depression } \\
\text { symptoms }\end{array}$} & \multicolumn{4}{|c|}{ Severe hostility symptoms } & \multicolumn{4}{|c|}{ Severe symptoms composite } \\
\hline & $\overline{\text { OR }}$ & p Value & OR & p Value & OR & p Value & OR & p Value & $\overline{\text { OR }}$ & p Value & OR & p Value & $\overline{\text { OR }}$ & p Value & OR & p Value \\
\hline \multicolumn{17}{|l|}{ Groups } \\
\hline Police officers 1 (Ref.) & 1 & & & & 1 & & & & 1 & & & & 1 & & & \\
\hline Police officers 2 (Ref. second column) & 0.53 & 0.13 & 1 & & 0.41 & 0.01 & 1 & & 0.56 & 0.07 & 1 & & 0.49 & 0.01 & 1 & \\
\hline Bank employees, not victim robbery & 1.16 & 0.68 & 2.21 & 0.00 & 1.02 & 0.94 & 2.51 & 0.00 & 1.25 & 0.43 & 2.22 & 0.00 & 1.22 & 0.38 & 2.49 & 0.00 \\
\hline Bank employees, victim robbery & 4.14 & 0.00 & 7.89 & 0.00 & 1.98 & 0.04 & 4.86 & 0.00 & 2.03 & 0.03 & 3.62 & 0.00 & 2.25 & 0.00 & 4.59 & 0.00 \\
\hline Psychiatric hospital employees & 1.68 & 0.21 & 3.19 & 0.00 & 1.47 & 0.22 & 3.61 & 0.00 & 1.22 & 0.55 & 2.17 & 0.00 & 1.41 & 0.20 & 2.89 & 0.00 \\
\hline Trainees AT & 4.40 & 0.00 & 8.38 & 0.00 & 4.24 & 0.00 & 10.41 & 0.00 & 3.69 & 0.00 & 6.56 & 0.00 & 3.90 & 0.00 & 7.96 & 0.00 \\
\hline Soldiers, not deployed before & 0.98 & 0.96 & 1.86 & 0.08 & 0.58 & 0.12 & 1.42 & 0.25 & 2.02 & 0.02 & 3.59 & 0.00 & 1.41 & 0.18 & 2.88 & 0.00 \\
\hline Soldiers, deployed before & 0.80 & 0.63 & 1.53 & 0.27 & 0.62 & 0.18 & 1.52 & 0.19 & 1.83 & 0.05 & 3.26 & 0.00 & 1.28 & 0.35 & 2.62 & 0.00 \\
\hline Firefighters & 0.64 & 0.43 & 1.21 & 0.71 & 1.12 & 0.77 & 2.74 & 0.00 & 1.28 & 0.50 & 2.28 & 0.01 & 1.16 & 0.64 & 2.36 & 0.00 \\
\hline Social welfare & 3.10 & 0.01 & 5.90 & 0.00 & 2.15 & 0.04 & 5.29 & 0.00 & 2.31 & 0.03 & 4.10 & 0.00 & 1.73 & 0.10 & 3.54 & 0.00 \\
\hline \multicolumn{17}{|l|}{ Education } \\
\hline Low medium & 1 & & & & 1 & & & & 1 & & & & 1 & & & \\
\hline High medium & 1.70 & 0.00 & 1.63 & 0.00 & 2.18 & 0.00 & 2.15 & 0.00 & 1.34 & 0.00 & 1.31 & 0.01 & 1.63 & 0.00 & 1.60 & 0.00 \\
\hline \multicolumn{17}{|l|}{ Age } \\
\hline $18-30$ & 1 & & & & 1 & & & & 1 & & & & 1 & & & \\
\hline $31-35$ & 0.89 & 0.43 & 0.83 & 0.25 & 0.89 & 0.36 & 0.83 & 0.16 & 1.17 & 0.23 & 1.14 & 0.31 & 1.21 & 0.09 & 1.15 & 0.22 \\
\hline $46-65$ & 0.96 & 0.79 & 0.93 & 0.63 & 1.01 & 0.95 & 0.96 & 0.73 & 1.11 & 0.39 & 1.12 & 0.39 & 1.12 & 0.29 & 1.09 & 0.44 \\
\hline \multicolumn{17}{|l|}{ Gender } \\
\hline Males & 1 & & & & 1 & & & & 1 & & & & 1 & & & \\
\hline \multirow{2}{*}{ Females } & 0.86 & 0.19 & 0.85 & 0.18 & 0.87 & 0.13 & 0.85 & 0.10 & 0.64 & 0.00 & 0.63 & 0.00 & 0.79 & 0.00 & 0.78 & 0.00 \\
\hline & \multicolumn{4}{|c|}{$\begin{array}{l}\text { Very severe anxiety } \\
\text { symptoms }\end{array}$} & \multicolumn{4}{|c|}{$\begin{array}{l}\text { Very severe depression } \\
\text { symptoms }\end{array}$} & \multicolumn{4}{|c|}{$\begin{array}{l}\text { Very severe hostility } \\
\text { symptoms }\end{array}$} & \multicolumn{4}{|c|}{$\begin{array}{l}\text { Very severe symmtoms } \\
\text { composite }\end{array}$} \\
\hline \multicolumn{17}{|l|}{ Groups } \\
\hline Police officers 1 (Ref.) & 1 & & & & 1 & & & & 1 & & & & 1 & & & \\
\hline Police officers 2 (Ref. second column) & 0.43 & 0.35 & 1 & & 0.86 & 0.85 & 1 & & 0.71 & 0.69 & 1 & & 0.66 & 0.56 & 1 & \\
\hline Bank employees, not victim robbery & 0.58 & 0.49 & 1.36 & 0.65 & 1.97 & 0.36 & 2.30 & 0.07 & 1.83 & 0.41 & 2.57 & 0.05 & 2.26 & 0.18 & 3.40 & 0.00 \\
\hline Bank employees, victim robbery & 3.53 & 0.12 & 8.27 & 0.00 & 6.84 & 0.01 & 7.98 & 0.00 & 4.60 & 0.05 & 6.45 & 0.00 & 6.92 & 0.00 & 10.44 & 0.00 \\
\hline Psychiatric hospital employees & 0.33 & 0.36 & 0.77 & 0.82 & 4.48 & 0.05 & 5.23 & 0.00 & 2.34 & 0.29 & 3.29 & 0.04 & 3.70 & 0.04 & 5.59 & 0.00 \\
\hline Trainees AT & 3.35 & 0.10 & 7.87 & 0.00 & 7.64 & 0.01 & 8.92 & 0.00 & 4.69 & 0.03 & 6.58 & 0.00 & 7.35 & 0.00 & 11.08 & 0.00 \\
\hline Soldiers, not deployed before & 0.51 & 0.51 & 1.21 & 0.84 & 0.26 & 0.27 & 0.30 & 0.27 & 1.83 & 0.45 & 2.57 & 0.11 & 1.39 & 0.63 & 2.10 & 0.16 \\
\hline Soldiers, deployed before & 0.00 & 1.00 & 0.00 & 1.00 & 0.61 & 0.62 & 0.71 & 0.67 & 1.22 & 0.82 & 1.72 & 0.42 & 1.23 & 0.78 & 1.85 & 0.27 \\
\hline Firefighters & 0.00 & 1.00 & 0.00 & 1.00 & 1.17 & 0.87 & 1.37 & 0.70 & 1.17 & 0.87 & 1.65 & 0.55 & 1.18 & 0.85 & 1.77 & 0.41 \\
\hline Social welfare & 0.95 & 0.97 & 2.22 & 0.49 & 3.94 & 0.12 & 4.60 & 0.02 & 7.20 & 0.02 & 10.10 & 0.00 & 6.31 & 0.01 & 9.52 & 0.00 \\
\hline \multicolumn{17}{|l|}{ Education } \\
\hline Low medium & 1 & & & & 1 & & & & 1 & & & & 1 & & & \\
\hline High medium & 2.65 & 0.00 & 2.71 & 0.00 & 2.04 & 0.00 & 1.98 & 0.00 & 1.29 & 0.21 & 1.26 & 0.26 & 1.76 & 0.00 & 1.71 & 0.00 \\
\hline \multicolumn{17}{|l|}{ Age } \\
\hline $18-30$ & 1 & & & & 1 & & & & 1 & & & & 1 & & & \\
\hline 31-35 & 0.92 & 0.83 & 0.93 & 0.87 & 1.17 & 0.53 & 1.10 & 0.70 & 1.54 & 0.12 & 1.57 & 0.12 & 1.36 & 0.14 & 1.30 & 0.22 \\
\hline $46-65$ & 1.50 & 0.28 & 1.54 & 0.28 & 1.23 & 0.40 & 1.19 & 0.49 & 1.03 & 0.93 & 1.09 & 0.78 & 1.20 & 0.38 & 1.18 & 0.43 \\
\hline \multicolumn{17}{|l|}{ Gender } \\
\hline Males & 1 & & & & 1 & & & & 1 & & & & 1 & & & \\
\hline Females & 0.63 & 0.13 & 0.64 & 0.13 & 1.07 & 0.71 & 1.05 & 0.80 & 1.22 & 0.30 & 1.21 & 0.33 & 1.12 & 0.45 & 1.09 & 0.54 \\
\hline
\end{tabular}

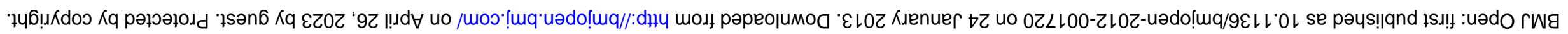

